\title{
La reorganización de los intelectuales \\ y militantes argentinos en Italia en los años '70
}

\author{
A reorganização dos intelectuais \\ e militantes argentinos na Itália dos anos 70
}

Giulia Calderoni $^{1}$

\begin{abstract}
Resumo Nos anos 1970, muitos argentinos deixaram seu país devido à violenta repressão militar, e alguns deles se refugiaram na Itália. Sua inserção no contexto italiano não foi fácil, sobretudo em razão da errônea associação entre o terrorismo italiano de extrema esquerda e os militantes argentinos, mesmo que estes sempre tenham buscado demarcar a distância entre seu ponto de vista e o, por exemplo, das Brigadas Vermelhas: para os exilados, a luta armada não tinha nenhum sentido num país democrático como a Itália. Apesar da heterogeneidade de motivação, orientação política e trajetória pessoal, estes indivíduos lograram se reorganizar e se unificar sob a égide da luta pela defesa dos direitos humanos e contra a repressão perpetrada pelos militares argentinos.
\end{abstract}

Palavras-chave exílio; reorganização; direitos humanos.

Résumé Dans les années 1970, nombreux argentins quittent leur pays à cause de la violente répression militaire et certains d'entre eux se réfugient en Italie. L'insertion dans le contexte italien n'a pas été facile, notamment en raison de l'erronée association entre le terrorisme italien d'extrême gauche et les militants argentins, même si ceux-ci ont toujours souligné la distance entre leur point de vue et celui, par exemple, des Brigades Rouges : pour les exilés, la lutte armée n'avait aucun sens dans un pays démocratique tel que l'Italie. Malgré l'hétérogénéité de motivation, d'orientation politique et de parcours personnels, ces individus ont réussi à se réorganiser et s'unifier sous l'égide de la lutte pour la défense de droits humains et contre la répression perpétrée par les militaires argentins.

Mots clé exil ; réorganisation ; droits humains.

Resumen En los años setenta muchos argentinos abandonaron su país por culpa de la violenta represión militar y algunos entre ellos se refugiaron en Italia. La inserción en el contexto italiano

\footnotetext{
${ }^{1}$ Licenciada en Mediación Lingüística e Intercultural, Sapienza Università di Roma; estudiante de maestría en Ciencias Sociales, IHEAL (Institut des Hautes Etudes de l'Amérique Latine) - Sorbonne Nouvelle, Paris. Título de la investigación en andamiento: Los exiliados argentinos en Italia en los años Setenta y Ochenta: entre la indiferencia de las instituciones y la solidaridad de la sociedad civil. E-mail: calderonigiulia@ gmail.com.
}

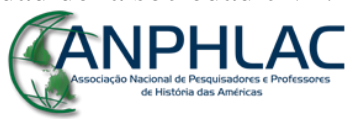

Revista Eletrônica da ANPHLAC, ISSN 1679-1061, N. 19, p. 129-151, jul./dez., 2015. http://revista.anphlac.org.br 
no fue fácil, sobre todo por causa de la errónea asociación entre el terrorismo italiano de extrema izquierda y los militantes argentinos, aunque los exiliados más de una vez afirmaron que para ellos la lucha armada no tenía sentido en un país democrático como Italia, subrayando la distancia existente entre su punto de vista y el de las Brigadas Rojas. A pesar de la heterogeneidad de las motivaciones, de la orientación política y de los itinerarios personales, estos individuos llegaron a reorganizarse y a juntarse bajo la égida de la lucha por la defensa de los derechos humanos y contra la represión perpetrada por la Junta argentina.

Palabras clave exilio; reorganización; derechos humanos.

\section{Artigo recebido em: 01/09/2015}

Artigo aprovado para publicação em: 03/12/2015

Estudiar el fenómeno del exilio es importante en la medida que permite abordar diferentes temáticas vinculadas con este objeto de investigación. El exilio puede ser un prisma para analizar tanto el contexto histórico-político del país de salida de los exiliados como también la situación del país de llegada. Al mismo tiempo es posible observar cómo la experiencia del exilio influye sobre el perfil socio-político de los exiliados. Éste es precisamente uno de los interrogantes a los cuales queremos contestar a lo largo del presente artículo: ¿qué resonancia tuvo el contexto del país de acogida sobre los exiliados? ¿De qué manera se reorganizaron al llegar a Italia y en qué modo los acontecimientos italianos se reflejaron sobre la actitud de los exiliados?

\section{Una caracterización del exilio}

Antes que todo hay que definir el concepto de "exilio": generalmente, esta palabra indica un alejamiento de la patria. El término deriva del latín exilium, que a su vez viene de la palabra exul, compuesto par ex y solum, así que su significado literal es "fuera del suelo" y, por extensión, "fuera de la patria". Cuando se habla de exilio, casi siempre se sobrentiende "exilio político" porque la imposibilidad para el individuo de quedarse en su país y la obligación a desplazarse casi siempre están asociadas a razones políticas.

\section{GANPHLAC}

Revista Eletrônica da ANPHLAC, ISSN 1679-1061, №. 19, p. 129-151, jul./dez., 2015.

http://revista.anphlac.org.br 
Cuando se habla del exilio argentino, se hace referencia a la salida del país de una parte de la población estimada entre 300.000 y 500.000 personas (JENSEN, 2010, p. 20). No hay que olvidarse del carácter multiforme del exilio: las causas que empujan al abandono del propio país son múltiples aunque en el origen haya una exclusión institucional muy fuerte (SNAJDER; RONIGER, 2009, p. 3). El individuo puede salir del país por razones políticas (en la mayoría de los casos de exilio) o económicas o familiares (en estos casos hablamos más bien de "migración").

No es fácil establecer una línea entre los casos de exilio y migración porque hay una multitud de factores que influencian la decisión de irse. Incluso en el caso del exilio político se puede pensar en la existencia de una componente de libre albedrío aunque en la percepción de los exiliados no haya sido así. Varios de ellos siempre afirmaron que "no hubo libre albedrío, que la decisión de huir fue una decisión forzada e impuesta por las circunstancias políticas desencadenadas por la represión militar" (LOLICATO, 2011, p. 197). Sin embargo, la mayoría de estos relatos presentan un carácter de autolegitimación; mejor dicho, la mayoría de los exiliados vivió el exilio como una condena y afectados por un sentimiento de doble culpabilidad: por haberse ido y por haber sobrevivido (FRANCO, 2008, p. 27).

Un elemento ulterior para aclarar la dificultad de definición del carácter arbitrario o impuesto del exilio se halla en la falta de institución de una "pena de exilio". Los exiliados vivían su condición como una imposición, como una elección forzada, como la única manera de salvar la vida; del otro lado el régimen militar "no estableció oficialmente la salida y la prohibición de regreso (con algunas excepciones)" (FRANCO, 2008, p. 39). De ahí que a nivel legal estas salidas se consideraron "voluntarias" aunque fueron en cierta manera "obligadas" por las circunstancias políticas.

El exilio es un fenómeno sociopolítico de la historia contemporánea de Europa, que incluye un elemento de voluntad política propia inexistente en fenómenos de otras épocas por muy similares que puedan parecer. La expulsión, el destierro, la proscripción o la deportación no pueden equipararse con él, pues son actos despóticos de quien detenta el poder y, por tanto, carentes de voluntariedad propia para quien lo sufre. (ABELLÁN, 2001, p. 108).

\section{CANPHLAC}

Revista Eletrônica da ANPHLAC, ISSN 1679-1061, N. 19, p. 129-151, jul./dez., 2015.

http://revista.anphlac.org.br 
En el caso del exilio argentino hay que subrayar que no se trató de un desplazamiento inmediato y violento, como en el caso de los chilenos, sino de un fenómeno diluído en el tiempo, "una migración a cuenta gotas y conformada por miles de salidas forzadas/condicionadas que se sucedieron a lo largo de toda la etapa dictatorial, aunque tuvieron un clímax entre 1976 y 1979” (JENSEN, 2010, p. 21). Según Silvina Jensen, el exilio argentino se caracterizó por su carácter desordenado, es decir por el hecho de ser el resultado de decisiones individuales: el exilio se presentó a estos individuos como la única solución frente a una violencia creciente y por una represión casi indiscriminada.

A pesar de este carácter desordenado y de su heterogeneidad, el exilio argentino fue un fenómeno que tuvo una dimensión de clase bastante marcada (FRANCO, 2008, p. 41). Principalmente salieron del país personas que formaban parte de la clase media y que tenían un nivel educativo medio-alto.

Para entender el fenómeno del exilio argentino en Italia en todas sus facetas se necesita hacer un paso atrás y enfocarse sobre las causas que llevaron a muchos argentinos a dejar sus familias y su país de origen para refugiarse en Italia. Sin duda tenemos que hacer referencia al régimen militar que se instala en Argentina el 24 de marzo de 1976 tras un golpe de estado. Conocida bajo el nombre de Proceso de Reorganización Nacional, esta dictadura será la más feroz jamás experimentada por Argentina y llevará mucha gente a escapar de su país para salvar la vida. Sin embargo, las salidas no empiezan después del golpe del 24 de marzo, sino algunos años antes: en Italia, los primeros "exiliados" argentinos llegan en 1974. Antes del establecimiento formal del régimen militar, la Triple A (Alianza Anticomunista Argentina) de José López Rega ya había instalado un clima de terror ${ }^{2}$.

El éxodo no empezó el día del golpe. Fue en el marco de la violencia originada por el accionar de bandas parapoliciales y paramilitares que hicieron su aparición en los últimos meses del gobierno de Juan D. Perón y alcanzaron su clímax bajo la presidencia de su esposa María Estela Martínez, que el lento goteo de exilios comenzó a perfilarse. Como indicaba la prensa española en los primeros días de marzo de 1976, la Argentina había comenzado a expulsar militantes de izquierda, líderes sindicales,

\footnotetext{
2 José López Rega (1916-1989), fundador de la Triple A y ministro del Bienestar Social durante el último gobierno de Perón (1973-1976). Se convierte en el símbolo de la derecha peronista; durante la presidencia de "Isabelita", viuda de Perón, ejerce de facto el poder hasta el golpe de estado del 24 de marzo de 1976. Murió en Buenos Aires en 1989, en la espera del juicio por los crímenes cometidos por los escuadrones de la muerte de la Triple A.
}

\section{CANPHLAC}

Revista Eletrônica da ANPHLAC, ISSN 1679-1061, N. 19, p. 129-151, jul./dez., 2015.

http://revista.anphlac.org.br 
periodistas, intelectuales, artistas y hasta deportistas durante el gobierno de PerónPerón. Esta diáspora fruto de un clima de intolerancia, intimidación, amenazas, asesinatos, torturas, listas negras y bombas, reconocía su origen en el accionar represivo de la Alianza Anticomunista Argentina (AAA) que operaba bajo el paraguas del Ministerio de Bienestar Social y de su titular José López Rega. Sus principales blancos fueron militantes políticos de larga trayectoria y compromiso ligados al peronismo de izquierda y Montoneros, pero también de la izquierda marxista y hasta del radicalismo. (JENSEN, 2010, p. 18-19)

Este flujo se intensifica en los primeros años de la dictadura, entre 1976 y 1978 y sigue hasta comienzos de los años Ochenta. Con la vuelta a la democracia y la elección de Alfonsín $^{3}$, gran parte de los exiliados regresaron a Argentina, aunque algunos decidieron establecerse en Italia de manera definitiva.

\section{La llegada: ¿quiénes eran estos militantes?}

El flujo de exiliados argentinos en Italia fue importante no tanto desde el punto de vista cuantitativo, sino cualitativo. Mejor dicho, el caudal de argentinos que huyeron a Italia no fue relevante pero sí lo fue su composición: muchos intelectuales (periodistas, artistas, dirigentes) e incluso representantes de las cúpulas de Montoneros ${ }^{4}$ y del Partido Revolucionario de los Trabajadores (PRT) ${ }^{5}$. Un elemento que es necesario remarcar es la falta de concesión del derecho de asilo político a los exiliados argentinos, que nunca obtuvieron el estatuto de "refugiados", al contrario de los exiliados chilenos llegados a Italia después del 11 de septiembre de 1973. Ésta es solamente una de las innumerables diferencias en el tratamiento de argentinos y chilenos por parte del Estado italiano y explica porqué nunca se supo con exactitud cuál fue el total de argentinos que se refugiaron a Italia. Además, muchos de ellos se

\footnotetext{
${ }^{3}$ Raúl Alfonsín (1927-2009) fue el primer presidente democráticamente electo después la dictadura de 1976-1983. ${ }^{4}$ Organización político-militar peronista creada a la mitad de los años sesenta en Córdoba. Nació de la confluencia de los católicos de izquierda y el ala progresista del Movimiento Peronista. Lucharon en favor del regreso de Perón, pero a su vuelta en 1973 fueron desconocidos por su propio mentor y volvieron a la clandestinidad.

${ }^{5}$ El Partido Revolucionario de los Trabajadores fue un partido argentino de izquierda, fundado en 1965 y nacido de la fusión de dos frentes revolucionario, uno de inspiración guevarista y el otro trotskista.

${ }^{6}$ En Italia el estatuto de "refugiado" solo se concedía a los individuos que provenían de los países de la Europa del Este. Excepcionalmente los chilenos disfrutaron del derecho de asilo político.
}

\section{GANPHLAC}

Revista Eletrônica da ANPHLAC, ISSN 1679-1061, N. 19, p. 129-151, jul./dez., 2015.

http://revista.anphlac.org.br 
confundieron con la población local, bajo la figura de antiguos migrantes italianos o descendientes de ellos volviendo a Italia.

\section{Las tres oleadas del exilio}

El exilio argentino se caracterizó por su heterogeneidad: heterogeneidad de proveniencia social, de motivaciones, de proyectos. Sin embargo, podemos identificar tres oleadas de exiliados (BERNARDOTTI, 2004, p. 50 y siguientes).

Como dijimos anteriormente, los primeros argentinos llegaron a Italia antes del golpe, es decir entre 1974 y 1976. Éstos eran sobre todo intelectuales, políticos, periodistas, profesores universitarios y artistas escapando la represión de los escuadrones de la muerte de López Rega en cuanto posibles blancos de la represión anticomunista. La huida representó entonces una medida preventiva para salvarse.

Sin embargo, muchos de los exiliados no eran personas que estaban comprometidas en la política argentina y por esto perseguidos por el gobierno. Se trataba (más bien) de individuos que huían porque no se reconocían en la acción represora de López Rega ni en la lucha armada. No obstante, entre ellos había intelectuales que se habían comprometido para que todo el mundo supiera lo que verdaderamente estaba pasando en Argentina. Tan es así que los que se quedaron en Roma fundaron el CAFRA, el Comité Antifascista contra la Represión en Argentina.

La segunda oleada del exilio argentino se ubica entre finales de 1976 y finales de 1978. En esta época llegaron los blancos principales de la represión, es decir los militantes y los dirigentes de las organizaciones armadas. Para ellos, el exilio representó una ocasión para seguir con la actividad política y preparar el regreso a Argentina. En Italia, estos individuos podían contar con el apoyo del escritor Juan Gelman ${ }^{7}$ y de Oscar Bidegain, ex gobernador de Buenos Aires y amigo de Lelio Basso $^{8}$, personaje clave en este contexto. Roma, en cuanto

\footnotetext{
${ }^{7}$ Poeta argentino. Exiliado, vivía en Roma.

8 1903-1078: senador italiano, personaje histórico de la Primera República, fue miembro del Tribunal Russel, creado para denunciar los crímenes estadounidenses cometidos en Vietnam. En 1973, Lelio Basso crea la Fundación Lelio y Lisli Basso en Roma y tres años más tarde la Fundación Internacional y la Lega Internazionale per i Diritti e la Liberazione dei Popoli.
}

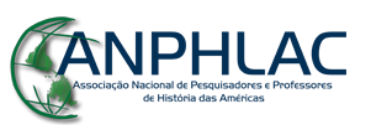

Revista Eletrônica da ANPHLAC, ISSN 1679-1061, №. 19, p. 129-151, jul./dez., 2015. http://revista.anphlac.org.br 
centro político del país, fue uno de las centros principales de la segunda oleada y se destacó entonces como "punto de llegada de los dirigentes de las organizaciones armadas y de las personalidades más destacadas de la vida política, sindical e intelectual del país” (LOLICATO, 2011, p. 65).

La última oleada tuvo lugar entre finales de 1978 y el final de la dictadura. En esta época llegaron sobre todo los familiares de los desaparecidos, con el objetivo de denunciar la desaparición de sus hijos, maridos, familiares, etc. Inicialmente se apoyaron en el CAFRA y en algunas parroquias pero empezaron a organizarse por su cuenta rápidamente. Es en esta tercera etapa que se observa la emergencia de una más fuerte solidaridad por parte de la población italiana.

El referente común a estas tres etapas es la lucha por la defensa de los derechos humanos: tanto los intelectuales como los familiares entendieron que la única manera para sacar a la luz la situación argentina era la denuncia de las atrocidades cometidas por la dictadura.

\section{¿Por qué Italia?}

Si observamos in toto el fenómeno del exilio argentino en estos años, se puede remarcar que no se dirigió masivamente hacia los países vecinos - Chile, Brasil, Bolivia, Uruguay ${ }^{9}$. El único país de América Latina fuertemente interesado por la ola migratoria fue México. Muchos exiliados se refugiaron en Europa, no solamente en países como Italia, España y Francia, que tenían fuertes vínculos histórico-culturales con Argentina, sino también en Suecia, Holanda y otros países del Norte de Europa que ofrecían un sistema de acogida muy organizado.

Entre las razones que contribuyeron a la elección de Italia, primero se destacan los vínculos familiares y culturales. La presencia de la cultura italiana era muy fuerte en Argentina; al mismo tiempo, Italia tenía una imagen positiva de este país que había acogido numerosos

\footnotetext{
${ }^{9}$ Probablemente esta decisión dependía del clima extremadamente represivo que existía en los países cercanos y que exponía a los prófugos a riesgo de ser capturados y torturados. En 1992 en los archivos de Paraguay se descubrirá la documentación relativa a la existencia de un acuerdo entre los servicios secretos y la policía de Argentina, Bolivia, Brasil, Chile, Paraguay y Uruguay. Este acuerdo, hoy día conocido como "Plan Condor", fue establecido en 1975 y planteaba la colaboración de los gobiernos de dichos países para facilitar la captura de eventuales refugiados políticos.
}

\section{GANPHLAC}

Revista Eletrônica da ANPHLAC, ISSN 1679-1061, N. 19, p. 129-151, jul./dez., 2015.

http://revista.anphlac.org.br 
italianos en el siglo anterior. El último factor es muy interesante, como se nota en esta entrevista:

\begin{abstract}
Los argentinos [...] se disgregaron, porque muchísimos argentinos son italianos, yo soy italiano. Y muchísimos argentinos tenían familia en Italia y así que fueron directamente a sus pueblos, se vincularon con sus abuelos o con sus tíos o quien sea, volvieron a establecer un ligamen y fueron absorbidos por Italia. Nosotros no sabemos cuántos argentinos emigraron a Italia. No lo sabe nadie, ni la Embajada, ni nadie (...).Y no se detuvieron los argentinos en las grandes ciudades como ocurre con otras inmigraciones, es una inmigración distinta. No es que, casi todos los emigrantes se detienen en las grandes ciudades, y después se pierden y se dislocan. Los argentinos no, [...], estos fenómenos de los emigrantes, esos procesos que marcan la estación, los lugares de agregación, los argentinos no lo tuvieron, porque directamente se vincularon con el país, o ya venían directamente vinculados con el país. Esperando que alguien los viniese a buscar, casi, ¿no? Y entonces muchos argentinos, entraron a formar parte de Italia. Además, muchos éramos jóvenes y se casaron, hicieron matrimonios con italianas y también ahí, hasta perdieron el idioma, casi (...). Porque casi todos los argentinos que vinieron a Italia no eran extranjeros. O lo eran mucho menos. Lo eran mucho menos por aquel motivo de sangre, pero también por aquel motivo cultural. (Entrevista de Luis por LOLICATO, 2011, p. 373).
\end{abstract}

Se nota claramente que el vínculo entre los argentinos e Italia no es un vínculo cualquiera: los exiliados buscaban las familias de los padres, de los abuelos. El viaje a Italia no representó solamente un viaje para salvar la vida, sino también un viaje en pos de sí mismo, de las raíces. A veces, esta búsqueda desembocó en la asimilación - jamás total, obviamente - de la cultura del país de acogida, considerada la cultura de los antepasados, de la antigua patria. De ahí la dificultad de establecer con exactitud el caudal del exilio argentino: llegando a Italia, muchos argentinos se hundieron a tal punto en este universo cultural que renunciaron al propio, tal vez en la tentativa de olvidar la dura realidad de la cual huían. A pesar de esto, hubo individuos que, aun reconociendo sus raíces italianas, no renunciaron a la identidad argentina sino que lucharon intensamente por la patria lejana.

Sin embargo, la elección de Italia no se debe exclusivamente a razones "afectivas", sino también al dinamismo de la política italiana de los años setenta: "uno de los motivos principales para la elección de Italia [...] fue el interés por la situación italiana de entonces, llena de fermentos políticos, culturales y sociales" (BERNARDOTTI, 2004, p. 53). A pesar de la tensión debida a la acción del terrorismo "negro" y "rojo", a pesar de la crisis económica, Italia se mostraba a los exiliados como un lugar estimulante, quizás por el increíble éxito del

\title{
GANPHLAC
}

Revista Eletrônica da ANPHLAC, ISSN 1679-1061, N. 19, p. 129-151, jul./dez., 2015.

http://revista.anphlac.org.br 
Partido Comunista dirigido por Enrico Berlinguer ${ }^{10}$. No hay que olvidar que se trataba del contexto de emergencia del Eurocomunismo ${ }^{11}$. En aquel momento, el PCI $^{12}$ vivía su edad del oro y un tercio de los italianos había votado por el PCI en ocasión de las elecciones políticas de $1976^{13}$. La fascinación que ejercía la situación italiana era manifiesta, como se nota en las palabras de Julio Santucho:

\begin{abstract}
Muchos argentinos vienen a Italia porque pueden hacer valer la doble ciudadanía, porque existe esta relación con la familia. En nuestro caso fue una elección política, [...]en el sentido que buscamos el país en el que era mayormente posible hacer una experiencia de este tipo, donde hubiese además una situación política interesante. Italia en aquella época tenía un gran Partido Comunista. Era el periodo, en el '76, de las elecciones europeas, del "sorpasso", llegué en un momento de gran entusiasmo, de euforia. Por un lado, desde este punto de vista, Italia era el país más indicado de Europa, el país donde la izquierda, no sé si decir era más fuerte pero seguramente soñaba más, tenía más ambiciones, una fuerte carga de ideales (Entrevista de Julio Santucho por BONGIOVANNI, 1998, p. 66).
\end{abstract}

En las palabras de Santucho se evidencia un elemento interesante: muchos argentinos se servían de la doble nacionalidad. Esta posibilidad estaba garantizada por la ley italiana . $^{\circ} 282$ del 18 de mayo de 1973, conforme a la cual los ciudadanos italianos argentinos podían adquirir respectivamente la nacionalidad argentina e italiana sin perder la de origen ${ }^{14}$. Sin embargo, para obtener la nacionalidad, un argentino debía demostrar sus orígenes italianos $\mathrm{y}$, a veces, incluso sus padres (o abuelos) tenían que seguir las normas de procedimiento para la obtención de la doble nacionalidad.

101922 -1984. Secretario general del Partido Comunista Italiano desde 1972 hasta su muerte. Fue un personaje clave de la política italiana de la posguerra y uno de los fautores del Eurocomunismo.

${ }^{11}$ El Eurocomunismo fue una tendencia ideológico-política sostenida por los Partidos Comunistas de Italia, Francia y España. Miraba a un marxismo que estuviera a mitad camino entre el leninismo y el socialismo.

${ }^{12}$ Partido Comunista Italiano.

${ }^{13}$ Se trata de un momento clave de la historia política italiana del siglo XX. Por primera vez, el Partido Comunista obtiene casi el mismo porcentaje de la Democracia Cristiana, partido que gobernó Italia durante más de 30 años. Sin embargo, el PCI no llegará al poder por culpa de las perturbaciones a finales de los años setenta, como el asesinato de Aldo Moro y el fin de las mediaciones con la DC para la realización del compromesso storico.

${ }^{14}$ En Italia la nacionalidad se atribuye en base a lo ius sanguinis, es decir que se transmite del padre al hijo aunque este no haya nacido o nunca haya vivido en Italia. El gobierno italiano promulgó esta ley para favorecer el regreso de los migrantes o de sus descendientes. Para obtener la nacionalidad italiana era suficiente demonstrar que uno de los padres, de los abuelos o de los bisabuelos nunca había renunciado formalmente a la nacionalidad italiana.

\title{
8ANPHLAC
}

Revista Eletrônica da ANPHLAC, ISSN 1679-1061, N. 19, p. 129-151, jul./dez., 2015.

http://revista.anphlac.org.br 
Además, la presencia del Vaticano en el territorio italiano empujó a los familiares de los desaparecidos a instalarse en Roma para buscar un contacto con el Papa, la máxima autoridad capaz de condenar moralmente la Junta Militar argentina.

Tras esta presentación general de los exiliados, podemos pasar a la presentación del impacto en Italia y la manera en la que se organizaron en esta realidad desconocida. No hay que olvidar la envergadura de este choque: muchos exiliados nunca habían viajado a Italia ni hablaban italiano. El desafío era enorme: empezar una nueva vida en un contexto desconocido y ajeno.

\section{Los intelectuales se comprometen: el CAFRA}

Desde el primer momento, los intelectuales argentinos llegados a Italia intentaron movilizar la opinión pública - tanto italiana como mundial - respecto a lo que estaba pasando en Argentina. Por esto, el 16 de noviembre de 1974 fundaron el CAFA, el Comité Antifascista Argentino, sucesivamente llamado CAFRA, Comité Antifascista contra la Represión en Argentina. Esta organización fue el eje alrededor del cual se desarrolló la acción de denuncia de los crímenes que ocurrían en Argentina. La fundación de este comité es anterior al golpe de la junta de Videla: su objetivo era poner al corriente a la sociedad italiana (y por extensión la sociedad europea) de las torturas perpetradas por la Triple A de López Rega, cuyos escuadrones de la muerte se vieron implicados en numerosas torturas y asesinatos.

Es necesario subrayar que este comité se autodefine "antifascista" por razones muy precisas: el hecho de que se elija este adjetivo no es para nada casual. Los argentinos esperaban que este término tuviera un fuerte impacto sobre la sociedad italiana: el recuerdo del régimen fascista estaba vinculado a uno de los periodos más oscuros de la historia de la Italia unitaria. Además, la palabra "antifascista" evocaba la lucha partisana y despertaba las conciencias de los que habían luchado para eliminar el espectro del totalitarismo que flotaba en el país. Como afirmó Augusto Rodríguez, se trató de una elección instrumental "no porque pensáramos que eso fuera fascismo, sino porque pensábamos que ésa era una sigla que en Italia tenía un impacto inmediato”. (BERNARDOTTI, 2004, p. 63)

\section{CANPHLAC}

Revista Eletrônica da ANPHLAC, ISSN 1679-1061, N. 19, p. 129-151, jul./dez., 2015. 
La envergadura del CAFRA se debe no solamente a su acción de denuncia, sino también al hecho de ser la única organización de solidaridad que agrupaba tanto a los militantes como a los que no se habían comprometido en la lucha armada. A pesar de su composición heterogénea, el CAFRA siempre logró actuar de manera unitaria en virtud de su sumo objetivo: la denuncia de la represión perpetrada por los militares en Argentina. Esto se debe también a la efímera presencia de los militantes de la lucha armada, que no se quedaron en Italia de manera constante sino temporal, lo que permitió al Comité estar al margen de ideologías políticas. Sin embargo, la llegada de los militantes tuvo repercusiones sobre la orientación del CAFRA. Las tensiones que se crearon respecto a la imposibilidad de encontrar un punto de convergencia entre los intelectuales y los militantes llevaron algunos de los fundadores al alejamiento, como fue el caso de Miguel Ángel García y su mujer Susana Bonaldi.

A pesar de esto, en general se considera al CAFRA como un organismo que no cambió su estrategia no obstante la integración de miembros que venían de la lucha armada y que nunca adquirió una connotación política específica. Su línea de acción siempre se basó en la defensa de los derechos humanos y en la lucha en contra de la violencia y de la represión. Como lo afirma Maria Adriana Bernardotti:

\footnotetext{
un gran mérito del comité será el haber mantenido firme, durante los años de la dictadura, su tarea prioritaria de denuncia unitaria de la represión en Argentina, sorteando presiones y buscando una equidistancia entre las organizaciones más fuertes en el panorama del exilo. (2004, p. 59)
}

El CAFRA no actuó a solas, sino que podía contar con la ayuda de otros organismos italianos como la Lega Internazionale per i Diritti e la Liberazione dei Popoli ${ }^{15}$ creada por Lelio Basso y el Tribunal Russell II $^{16}$, junto a los cuales el CAFRA había empezado a trabajar ya en 1975. La acción del Comité se basaba principalmente en conferencias de prensa, difusión de noticias que llegaban de Argentina y eventos organizados para sensibilizar la opinión pública italiana.

\footnotetext{
15 Organismo para la defensa de los derechos humanos.

${ }^{16}$ En 1973, Lelio Basso empieza los trabajos para la creación de un segundo tribunal para condenar la represión puesta en marcha en América Latina por las dictaduras militares.
}

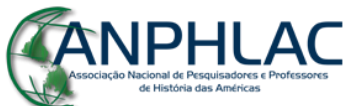

Revista Eletrônica da ANPHLAC, ISSN 1679-1061, N. 19, p. 129-151, jul./dez., 2015.

http://revista.anphlac.org.br 


\section{La reorganización política de los militantes}

Diferente fue la reorganización de los militantes: hay que decir que los que llegaron a Italia no compartían exactamente los mismos ideales políticos. Este dato es fundamental para comprender cómo se organizaron después de su llegada a Italia. Primero, estos individuos buscaron un diálogo con las fuerzas políticas italianas, a veces con resultados sorprendentes. El apoyo del Partido Comunista Italiano al PRT parece bastante lógico mientras que no era tan previsible el diálogo que se instauró entre los Montoneros y la Democracia Cristiana.

Roma, punto neurálgico de la política italiana, fue uno de los lugares clave para los dirigentes de Montoneros a la hora de establecer contactos, aunque los jefes montoneros nunca se instalaron de manera definitiva en la capital. Este grupo era bastante heterogéneo y comprendía intelectuales, periodistas, jefes de la organización, jóvenes de la JP o de la JUP ${ }^{17}$, etc. Se trataba de los testigos directos de la represión y de la violencia de la dictadura argentina: muchos entre ellos habían sido torturados y huían para salvarse. Como mencionamos antes, los Montoneros en Roma podían contar con la presencia de Juan Gelman y Oscar Bidegain, cercanos a la corriente progresista de la Democracia Cristiana y a la CISL $^{18}$. Gracias a la ayuda de Lelio Basso, el 20 de abril de 1977 se organizó la presentación del Movimiento Peronista Montoneros en Roma, en un hotel, en presencia de la prensa italiana (BERNARDOTTI, 2004, p. 60-61). Para el MPM ${ }^{19}$, se trató de un momento tanto importante cuanto peligroso: hay que recordar que la mayoría de los militantes vivía en Italia como clandestinos, con documentos falsos. No obstante, podían contar con el apoyo informal del PCI y de los sectores de izquierda de la DC. El PCI fue el partido que concretamente dio más sostén a los Montoneros: en 1979, el Partido Comunista le cedió a los del MPM una sede en Frattocchie, alrededor de Roma, para que se organizara la Contraofensiva ${ }^{20}$.

\footnotetext{
${ }^{17}$ La Juventud Peronista (JU) y Juventud Universitaria Peronista (JUP) eran dos formaciones de la izquierda peronista.

${ }^{18}$ Sindicato de inspiración cristiana, en aquel momento era cercano a la izquierda.

${ }^{19}$ Movimiento Peronista Montonero.

${ }^{20}$ La contraofensiva consistía en el regreso de un grupo de militantes para continuar la lucha armada y contrastar la represión de los militares. Hubo dos Contraofensivas, la primera en 1979 y la segunda en 1980: ambas fracasaron. Muchos de los exiliados - sobre todo los jóvenes que habían escapado de la represión y los que estaban reexaminando su ideología política - no participaron a la Contraofensiva.
}

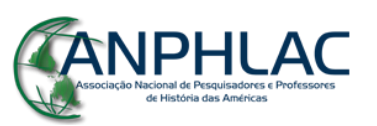

Revista Eletrônica da ANPHLAC, ISSN 1679-1061, N. 19, p. 129-151, jul./dez., 2015.

http://revista.anphlac.org.br 
Mientras los Montoneros se habían instalado sobre todo en los alrededores de Roma, los miembros del PRT se encontraban principalmente en el norte de Italia.

El caso del PRT es interesante porque su acción se diferenciaba de la del MPM: los militantes del Partido Revolucionario de los Trabajadores no se limitaron a una acción de denuncia y propaganda, sino que organizaron verdaderas escuelas para la formación de cuadros (BERNARDOTTI, 2004, p. 64-65). El exilio en Italia era una ocasión para reorganizarse políticamente y reflexionar sobre los errores que los habían llevado al fracaso. Además, el desarrollo de estas "escuelitas" en el norte de Italia captó la atención de los ex partisanos, los cuales empezaron a interesarse en las actividades de los exiliados y a ayudarlos. De esta manera, las escuelitas no se limitaron simplemente a la formación de guerrilleros sino también contribuyeron a sensibilizar una parte (si bien pequeña) de la población italiana. Sobre todo en el noroeste italiano, el recuerdo de la lucha antifascista por la liberación de Italia seguía siendo muy fuerte: los ex-combatientes asimilaban la lucha de estos jóvenes argentinos a la lucha que ellos mismos habían llevado a cabo 20 años atrás.

A pesar del apoyo local, la experiencia de las escuelitas terminó en mayo de 1979, tras la fractura interna al PRT después del VI Congreso.

\section{El alejamiento del compromiso directo y la experiencia del Colectivo Debate}

El colectivo Debate representó una de las pocas iniciativas culturales de los exiliados, junto a la experiencia del Teatro Núcleo de Ferrara. Los miembros del colectivo eran casi todos intelectuales o militantes de izquierda. Entre ellos encontramos ex-componentes del CAFRA - como Miguel Ángel García y Susana Bonaldi - y exiliados que no querían exponerse demasiado, en vista de un posible regreso a la Argentina. Esta experiencia representó un compromiso entre la militancia y la ausencia de acción y permitió un vínculo más blando con los acontecimientos argentinos. Además, dejó más libertad para los intercambios de ideas entre los exiliados y el contexto político-cultural italiano de la época, que representaba un verdadero ejemplo para los argentinos trasplantados en el Bel Paese. La actividad de este grupo no era muy práctica, sino más bien teórica. El Colectivo, en el cual incluso participaban algunos sindicalistas italianos, se ocupaba de dos revistas: Debate e Información Obrera.

\section{CANPHLAC}

Revista Eletrônica da ANPHLAC, ISSN 1679-1061, N. 19, p. 129-151, jul./dez., 2015.

http://revista.anphlac.org.br 
Debate quería reactualizar el pensamiento marxista gracias a la experiencia política internacional que había desembocado en la crisis de los años setenta, mientras que Información Obrera apuntaba a fundar un nuevo movimiento sindical autónomo en América Latina (BERNARDOTTI, 2004, p. 76). En efecto, el sistema sindical italiano representaba un verdadero ejemplo para los miembros del Colectivo, evidenciando la necesidad de una profunda reforma del sindicalismo en América Latina y la creación de un movimiento sindical independiente. Un tema remarcable de la revista era la crítica del terrorismo de la extrema izquierda italiana, como veremos más adelante.

\section{Las dificultades de los exiliados}

Al principio, los argentinos que llegaban a Italia encontraron muchas dificultades para integrarse en la sociedad italiana; a pesar de su inserción informal en los partidos, había una cierta desconfianza hacia ellos y sobre todo faltaba cualquier ayuda estatal. La ausencia del gobierno italiano en los asuntos que atañían los desterrados argentinos dependía de diferentes factores. Primero, los intereses comerciales entre Italia y Argentina eran demasiado fuertes para que el Estado italiano se comprometiera en la defensa de una causa que podía poner en riesgo los provechos de sus empresarios. Segundo, los exiliados argentinos encontraban una cierta dificultad para insertarse en la vida política italiana: si los militantes del PRT podían encontrar una tibia ayuda en los miembros del Partido Comunista Italiano, más difícil era la situación de los montoneros y de los peronistas en general. En Italia - y por extensión en Europa - donde la vida política se fundía en la distinción básica de izquierda-derecha, nunca se llegó a comprender la justa ubicación política del peronismo. Para algunos, el peronismo representaba un subrogado de los fascismos de los años treinta-cuarenta, debido a su carácter populista y a su ideología fuertemente influenciada por los totalitarismos europeos; de ahí que se asimilaban los peronistas a los neo-fascistas italianos. Para otros, los peronistas montoneros, con su acción desestabilizadora del orden y su estrategia de guerrilla urbana, se asemejaban a los grupos terroristas que en los años setenta estaban poniendo al Estado italiano bajo el yugo del terror y del miedo; la asimilación a las fuerzas brigadistas era casi inmediata. En una época tan

\section{CANPHLAC}

Revista Eletrônica da ANPHLAC, ISSN 1679-1061, Nº. 19, p. 129-151, jul./dez., 2015.

http://revista.anphlac.org.br 
peliaguda como los Anni di Piombo $^{21}$, la inserción de los exiliados se dificultó por la exacerbación de la violencia de las Brigadas Rojas ${ }^{22}$, a las cuales los militantes argentinos fueron asociados más de una vez. Era simple pensar que estos militantes llegando de la lucha armada habrían apoyado la acción terrorista de las Brigadas Rojas o de otros grupos de extrema izquierda. Al contrario, no existe ninguna prueba de una eventual colaboración entre los guerrilleros argentinos y el terrorismo italiano. Los miembros de Montoneros, de la Juventud Peronista o del PRT-ERP ${ }^{23}$, siempre evidenciaron las divergencias que existían entre su cultura política y la de los brigadistas. Para los exiliados argentinos, la lucha armada no tenía sentido en un país democrático como Italia. Más de una vez, los militantes exiliados expresaron su desconocimiento a la lucha terrorista italiana, subrayando cómo su acción en el extranjero se limitaba a una simple difusión de las noticias respecto a la situación argentina y a la lucha para la defensa de los derechos humanos.

una cosa importante para decir es que ninguno de los argentinos, casi todos provenientes de la lucha armada, tuvieron o llegaron a tener relaciones con el terrorismo italiano. Una parte, Montoneros sobre todo, podía tener relaciones con lo que era la Democracia Cristiana, Zaccagnini, la CISL, el sindicato democristiano que en ese momento tenía una gran posición hacia la izquierda; y todo lo que era el movimiento de ex PRT, FAL y diversas proveniencias, tenían el criterio que la lucha armada va utilizada en aquellos lugares donde no hay democracia, no en un país como Italia donde no había ninguna lógica para la lucha armada. Lo importante es entender que no hubo un solo argentino, y latinoamericano casi, vinculado a historias de terrorismo en Italia. [...] Fue una crítica inmediata a la guerrilla en Italia, a la lucha armada en Italia, porque nosotros posiblemente sabíamos el valor de la democracia y

${ }^{21}$ En el momento de la llegada de los exiliados argentinos Italia vivía el triste periodo llamado "Anni di Piombo", los Años de Plomo. Con este término se hace referencia a une época que va de 1968 hasta comienzos de los años Ochenta. Se trata de una década que se caracterizó por la violencia de la lucha armada de grupos terroristas tanto de la extrema derecha (Nuclei Armati Rivoluzionari, Ordine Nero) como de la extrema izquierda (Brigate Rosse, Prima Linea, GAP). Estos grupos, insatisfechos de la situación política italiana de la época, querían una desestructuración de la sociedad a través de la "estrategia de la tensión", que habría llevado el país a la instauración de un régimen autoritario (objetivo final del terrorismo "negro") o a la revolución del proletariado (meta del terrorismo "rojo"). El periodo de mayor violencia coincide con el momento de llegada de los argentinos y alcanza el ápice en 1978 con el secuestro y asesinato de Aldo Moro por las Brigadas Rojas.

${ }^{22}$ Las Brigate Rosse fueron una organización terrorista de inspiración marxista-leninista y guevarista. Actuaron en Italia en los años 1970-1980 con la finalidad de desestabilizar las instituciones. Fundadas en el 1970, empezaron a utilizar masivamente la violencia a partir de 1974. Su oposición al Compromesso storico entre PC y DC llevó los brigadistas a secuestrar (y luego asesinar) al presidente de la DC Aldo Moro. En 1979 empezó el declive de la organización que se escindió en 1982, aun continuando con su actividad criminal hasta 2003 bajo el nombre de Nuove Brigate Rosse.

${ }^{23}$ Ejército Revolucionario del Pueblo: grupo guerrillero de inspiración marxista, se considera el brazo armado del PRT.

\section{GANPHLAC}

Revista Eletrônica da ANPHLAC, ISSN 1679-1061, №. 19, p. 129-151, jul./dez., 2015.

http://revista.anphlac.org.br 
lo que podía significar Italia. No sé si nos contactaron, creo que supieron inmediatamente que nadie les iba a dar mucha pelota (Entrevista con J. Miglioli por BERNARDOTTI, 2002, p. 69).

Tanto los del PRT como los Montoneros publicaron más de un informe para declarar su desconocimiento de lo que estaba pasando en Italia. Citamos como ejemplo un extracto de un comunicado del MPM, redactado por Juan Gelman, Secretario Adjunto de la Secretaría de Prensa y editado en ocasión del asesinato de Aldo Moro ${ }^{24}$.

El desarrollo del accionar armado fuera de las condiciones que hemos descripto para nuestro país, es decir, careciendo de fundamente moral, jurídico y político, no sólo no constituye un método de lucha revolucionario, sino que se transforma objetivamente en un delito frente a las personas que padecen este accionar. (GELMAN, 1978, p. 1)

\section{El “Affaire Moro” y la ayuda del PCI}

A pesar de su distanciamiento del terrorismo italiano, la participación en la lucha armada en Argentina siguío representando para estos militantes un factor perjudicial para su inserción en la vida política de Italia. La supuesta participación en los actos de violencia de las Brigadas Rojas (BR) obstaculizaron relaciones directas con los partidos políticos, sobre todo en ocasión del secuestro y el asesinato de Aldo Moro, presidente de la Democracia Cristiana e intermediario entre la DC y el PCI para la realización del compromesso storico ${ }^{25}$. Como una parte de los exiliados venían de la guerrillera, asociar todos los desterrados a las BR parecía del todo natural. La realidad era muy diferente: los brigadistas nunca fueron un ejemplo para los militantes argentinos, que no encontraban algún sentido en la lucha de estos grupos. Más bien se identificaban con los ancianos ex-partisanos y con su lucha libertadora que puso fin al

\footnotetext{
${ }^{24}$ Se trata de una de las páginas sombras de la historia italiana de la posguerra. Aldo Moro (1916-1978) fue uno de los hombres políticos de relieve de la Primera República. Secretario de la Democracia Cristiana, había desempeñados varios cargos (Primer Ministro, Ministro de los Asuntos Extranjeros, etc.). El 16 de marzo de 1978 fue secuestrado por las Brigadas Rojas y su cuerpo sin vida fue encontrado el 9 de mayo del mismo año en una Renault 4 roja en Via Caetani, en Roma.

${ }^{25}$ Después del golpe de estado en Chile el 11 de noviembre de 1973, se explicita la voluntad del Secretario del Partido Comunista Italiano, Enrico Berlinguer, de buscar una alianza con la Democracia Cristiana y presentarse a las elecciones como una coalición. El Partido Comunista, que en estos años era el segundo partido italiano por número de votantes, seguía siendo excluido de la vida política por su vínculo con la URSS y su presunto carácter antidemocrático. El acercamiento del PC y de la DC habría permitido una colaboración entre los dos partidos más importantes de Italia y habría excluido definitivamente el Partido Socialista de la escena política.
}

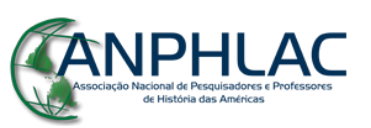

Revista Eletrônica da ANPHLAC, ISSN 1679-1061, №. 19, p. 129-151, jul./dez., 2015.

http://revista.anphlac.org.br 
régimen fascista. Para alejar toda sospecha de una posible participación en la acción de las BR, el MPM difunde un comunicado en el que "condena el secuestro del On. Aldo Moro y expresa su solidaridad con el pueblo italiano, con sus centrales sindicales y sus partidos políticos democráticos" (GELMAN, 1978, p. 2).

A pesar de estas tentativas, siempre se miró a los argentinos con desconfianza. El caso Moro representó un verdadero problema porque la mayoría de los militantes tenían documentos falsos y pudieron evitar problemas con los policías sólo gracias a la intervención del PCI, que abogó por ellos. Hay que decir que la ayuda del Partido Comunista se limitaba a una cierta solidaridad de base pero no podía exhibir algún apoyo oficial, sobre todo respecto a los Montoneros, cuya orientación política aparecía ambigua a los ojos del PCI.

Hasta los miembros del CAFRA tienen que confrontarse con las consecuencias del secuestro Moro. El 16 de marzo de 1978, el Comité había organizado una gran conferencia pública para denunciar la situación de los desaparecidos pero se anuló el evento por dos razones: primero, la falta de periodistas, todos ocupados con la desaparición de Moro; segundo, se quería evitar toda asociación entre los Argentinos y el secuestro del presidente de la DC. Augusto Rodríguez así recuerda dicho episodio:

\footnotetext{
Era el momento peor del terrorismo italiano cuando nosotros habíamos organizado la cosa más grande que hicimos: una Conferencia con los familiares. Llegaron a Roma de todo el mundo y justo el día programado para el encuentro fue el día del secuestro de Moro. Teníamos la conferencia de prensa para presentar toda la historia a los medios italianos; recuerdo que llegó Umberto Terracini, el senador [...], para contarnos lo que estaba sucediendo. Esto creaba muchas reservas: muchos perseguidos argentinos eran sospechados de terrorismo y si se hacía esta asociación los italianos buscarían mantenerse lo más lejos posible de los argentinos. (Entrevista de Augusto Rodríguez por BONGIOVANNI, 1988, p. 69).
}

Es interesante observar la resonancia que tuvo el asesinato de Moro sobre la política argentina, en particular la manera en la que los militares sacaron partido de esta ocasión para afirmar la existencia de una corriente más amplia del terrorismo internacional. La Junta instrumentalizó el infausto acontecimiento para justificar y autodeterminar su necesidad de estar en el poder en Argentina. Marina Franco (2002) presenta un ejemplo muy claro: en ocasión del funeral de Moro, Jorge Rafael Videla envió un mensaje al Gobierno italiano para expresar su sentido pésame: "nos sentimos hondamente conmovidos por el vil asesinato del Dr. Aldo

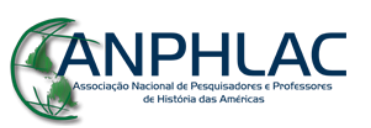

Revista Eletrônica da ANPHLAC, ISSN 1679-1061, №. 19, p. 129-151, jul./dez., 2015. http://revista.anphlac.org.br 
Moro y comprendemos vuestro dolor e indignación por haber vivido en horas no lejanas ominosos ataques desencadenados por ese terrorismo nihilista que azota Italia" (Clarín, 10/05/78, p. 30). La comparación de Videla quiere poner al mismo nivel la situación de caos causada por la guerrilla argentina y el terror provocado por las acciones del terrorismo italiano. Se sobreentiende la necesidad de una solución "a la argentina" y se destaca la voluntad de exaltar la victoria de los militares y la extirpación de la subversión en el país del Cono Sur. Hay que decir que en este periodo la prensa, tanto la argentina como la italiana, ofrecía una visión parcial de la situación que vivía el país del Cono Sur bajo el régimen de Videla. En particular modo, en Italia el obscurantismo mediático fue impulsado por la logia masónica Propaganda 2 (P2), que en aquellos años controlaba secretamente varios asuntos relativos a la política y la economía italiana.

\section{Conclusiones}

Como afirmamos a lo largo de este trabajo, la presentación de las organizaciones de los exiliados permite encontrar dos elementos de afinidad que unen a todos los desterrados argentinos en Italia: la denuncia de la represión y la defensa de los derechos humanos. Aun perteneciendo a distintas corrientes políticas, aun teniendo formaciones diferentes, los exiliados comprendieron que la única manera de captar la atención de los medios de comunicación y obtener visibilidad era la denuncia de la desaparición de ciudadanos italianos (o de origen italiano) en Argentina. A esto se añadía la tentativa de demostrar el carácter ineludible del exilio y justificarlo bajo el pretexto de poder actuar por el bien de Argentina, aun viviendo en el extranjero.

Además, la inserción en la sociedad italiana presenta características peculiares. Los desterrados políticos se integraron con dificultad en un espectro político de matriz europea, al contrario de los chilenos que tenían un sistema de partidos parecido al sistema europeo. Sin embargo, las diferentes estrategias que los militantes pusieron en marcha permitieron inscribir su reivindicación en un cuadro conceptual conocido, que remite a valores positivos y que se comparten entre todos (LOLICATO, 2011, p. 410); en particular, el ya mencionado intento de

\section{GANPHLAC}

Revista Eletrônica da ANPHLAC, ISSN 1679-1061, №. 19, p. 129-151, jul./dez., 2015.

http://revista.anphlac.org.br 
comparar su lucha a la de los partisanos italianos durante la Segunda Guerra Mundial. En cambio, las madres de los desaparecidos habían encontrado menos problemas: quizás dependió de las estructuras que las acogieron, sobre todo redes católicas cuya solidaridad chocaba con la indiferencia de las altas esferas de la jerarquía eclesiástica. Un elemento que seguramente jugaba a su favor era propiamente la condición de madres en búsqueda de los hijos desaparecidos, condición que acercaba la colectividad al sufrimiento de estas mujeres (DANGY, 2006, p. 2).

Todos los exiliados compartieron una sensación de impotencia frente a la realidad argentina y sufrieron al mismo tiempo por el abandono de las instituciones, que parecían indiferentes ante sus historias. Más de una vez se acusó al Gobierno italiano por su silencio cómplice. Excepto algunas intervenciones individuales, como en el caso de ciertos diputados, no se observó una verdadera voluntad de contrastar la experiencia dictatorial argentina.

A pesar de la conducta del Estado que los acogía, para los militantes la experiencia del exilio en Italia fue fundamental porque les permitió conocer una manera diferente de hacer política. Además, al llegar a Italia una parte de los militantes dejó a un lado la lucha y puso en marcha una relectura de su propio pasado político, teniendo en cuenta la nueva experiencia (LOLICATO, 2011, p. 208). No obstante, la reformulación de la identidad política no implicó una ruptura brutal con las ideas anteriores: se trató más bien de una renovación que se insertó en un flujo de continuidad con el pasado. Resulta más difícil definir si podemos hablar - y de qué manera - de una verdadera identificación común de los exiliados. El hecho de unirse para defender la misma causa ¿implicó una proyección identitaria? y/o ¿amplificó el sentido de pertenencia a una comunidad? Sólo podemos afirmar que el impacto con la sociedad italiana modificó para siempre la visión del mundo de los exiliados y esta experiencia los llevó a una toma de conciencia que difícilmente habría ocurrido en otras condiciones.

\section{Referencias Bibliográficas}

ABELLÁN, José Luís (coordinador). El exilio español de 1939, Madrid: Editorial Taurus, 1976.

\section{CANPHLAC}

Revista Eletrônica da ANPHLAC, ISSN 1679-1061, Nº. 19, p. 129-151, jul./dez., 2015.

http://revista.anphlac.org.br 
ABELLÁN, José Luís. El exilio como constante y como categoría, Madrid: Biblioteca Nueva, 2001.

ANGUITA, Eduardo; CAPARRÓS, Martín. La Voluntad, Buenos Aires: Grupo Editorial Norma, 1998, tomo III (1976-78).

BERNARDOTTI, María Adriana; BONGIOVANNI, Barbara. Aproximaciones al estudio del exilio argentino en Italia. In: YANKELEVICH, Pablo (coordinador). Represión y destierro: itinerarios del exilio argentino. La Plata: Ediciones Al Margen, 2004, p. 49-89.

BONASSO, Miguel. Diario de un clandestino. Buenos Aires: Planeta, 2001.

CALANDRA, Benedetta. De emigrantes a exiliados. Trayectorias de migración profesional y política entre el Cono Sud, Europa y Estados Unidos (1973-1983). Huellas de Estados Unidos. Estudios y debates desde América Latina, n. 3, septiembre 2012, p. 64-72. Disponible en:http://issuu.com/val_carbone/docs/numero_3_completo_sep_2012/1?e=9551889/7526771. Acceso en: veinte de junio, 2015.

CALANDRA, Benedetta. Entre el Sena y el Rio de la Plata. Memoria e identidad de los chicos del exilio argentino en Europa (1976-1983). DEP. Deportati, esuli, profughe. Rivista telematica di studi sulla memoria femminile, Università di Cà Foscari, Venezia, n. 3, p.21-31, 2005.

CASOLA, Natalia. El Partido Comunista argentino y el exilio en Europa durante la última dictadura militar. Caracterizaciones políticas, alianzas y disputas. Testimonios, $3^{\mathrm{e}}$ año, n. 3 , 2013.

CAVALLETTI, Valentina. Trasfigurazione. Una storia di desaparecidos, accoglienza e solidarietà. Roma: CENRI, 2006.

DANGY, Tatiana, Maternité et politique : la place et le rôle du mouvement des mères de la Place de Mai dans la démocratisation de l'Argentine, bajo la dirección de Bernard Labatut, Institut d'Etudes Politiques de Toulouse, Toulouse, 2006.

FANEGO, Delia Ana. Quebrantos: storie dell'esilio argentino. Roma: Nova Delphi, 2012.

\section{GANPHLAC}

Revista Eletrônica da ANPHLAC, ISSN 1679-1061, №. 19, p. 129-151, jul./dez., 2015.

http://revista.anphlac.org.br 
FRANCO, Marina, La campaña antiargentina: la prensa, el discurso militar y la construcción de consenso. Derecha, fascismo y antifascismo en Europa y Argentina, Argentina: Universidad de Tucumán, 2002, p. 195-225.

FRANCO, Marina. El exilio: argentinos en Francia durante la dictadura. Buenos Aires: Siglo XXI Editores Argentina, 2008.

GELMAN, Juan, Sobre el secuestro del On. Aldo Moro. Comunicado de prensa del MPM. Roma: 1978.

GUELAR, Diana; VIGEVANI JARACH, Vera; RUIZ, Beatriz. Los chicos del exilio. Buenos Aires: Ediciones El País de Nomeolvides, 2002.

JENSEN, Silvina. Los exiliados. La lucha por los derechos humanos durante la dictadura. Buenos Aires: Sudamericana, 2010.

JENSEN, Silvina; LASTRA, Soledad. Exilios: Militancia y represión. Nuevas fuentes y nuevos abordajes de los destierros de la Argentina de los años setenta. La Plata: Edulp, Memoria Académica, 2014.2 Disponible en: http://www.memoria.fahce.unlp.edu.ar/libros/pm.371/pm.371.pdf Acceso en: cuatro de junio, 2015.

LAACHER, Smaîn. Éléments pour une sociologie de l'exil, Politix 2005/1, n 69, p. 101-128, 2005.

LOLICATO, Andrea. Movilidad transnacional y movimientos sociales: las organizaciones solidarias de argentinos en Roma y Barcelona. Tesis de Doctorado en Antropología bajo la dirección de Joan Josep Pujadas Muñoz, Departamento de Antropología, Filosofía y Trabajo Social, Universitat Rovira I Virgili Tarragona, 2011.

MORETTI, Italo. I figli di Plaza de Mayo. Milano: Sperling \& Kupfer Editori, 2002.

ROCCHI, Fabrizio, Il regime militare argentino nella stampa italiana. 24marzo.it, Disponible en:

http://www.24marzo.it/index.php?module=pagemaster\&PAGE_user_op=view_page\&PAGE_ id=139. Acceso en: cinco de diciembre, 2014.

\section{GANPHLAC}

Revista Eletrônica da ANPHLAC, ISSN 1679-1061, N. 19, p. 129-151, jul./dez., 2015.

http://revista.anphlac.org.br 
RONIGER, Luis, Destierro y exilio en América Latina: Un campo de estudio transnacional e histórico en expansión. Disponible en: http://www.pacarinadelsur.com/home/abordajes-ycontiendas/318-destierro-y-exilio-en-america-latina-un-campo-de-estudio-transnacional-ehistorico-en-expansion. Acceso en: diez de junio de 2015.

Sexto Congreso del PRT en Italia, 26 de septiembre de 2006. Disponible en: http://nuestrahistoria70.blogspot.fr/2009/01/b073-sexto-congreso-del-prt-en-italia.html. Acceso en: 8 de junio de 2015.

SNAJDER, Mario; RONIGER, Luis. The politics of exile in Latin America. New York: Cambridge University Press, 2009.

TALLONE, Carla; VIGEVANI JARACH, Vera. Il silenzio infranto. Il dramma dei desaparecidos italiani in Argentina, Torino: Silvio Zamorani Editore, 2005.

TOGNONATO, Claudio. Affari nostri. Diritti umani e rapporti Italia-Argentina 1976-1983. Roma: Fandango, 2012.

YANKELEVICH, Pablo (dir.). Represión y destierro: itinerarios del exilio argentino. Buenos Aires: Ediciones Al Margen, 2004.

YANKELEVICH, Pablo; JENSEN, Silvina, (dir.). Exilios. Destinos y experiencias bajo la dictadura militar. Buenos Aires: Libros del Zorzal, 2007.

\section{Siglas}

AAA : Alianza Anticomunista Argentina (Triple A)

BR: Brigadas Rojas

CAFA: Comité Antifascista Argentino

CAFRA: Comité Antifascista contra la Represión en Argentina

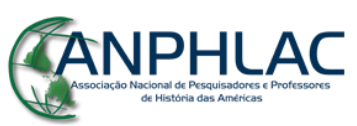

Revista Eletrônica da ANPHLAC, ISSN 1679-1061, №. 19, p. 129-151, jul./dez., 2015.

http://revista.anphlac.org.br 
DC: Democracia Cristiana

ERP: Ejercito Revolucionario del Pueblo

JP: Joventud Peronista

JUP: Joventud Universitaria Peronista

MPM: Movimento Peronista Montonero

PCI: Partido Comunista Italiano

PRT: Partido Revolucionario de los Trabajadores

\section{GANPHLAC}

Revista Eletrônica da ANPHLAC, ISSN 1679-1061, N. 19, p. 129-151, jul./dez., 2015.

http://revista.anphlac.org.br 